\title{
Modernización de las fuerzas armadas durante el reinado de Juan Carlos I
}

\section{Modernization of the Armed Forces During the Reign of Juan Carlos I}

\author{
Fernando Puell de la Villa ${ }^{1}$ \\ Instituto Universitario General Gutiérrez Mellado- \\ UNED (España) \\ ORCID: https://orcid.org/0000-0001-8107-560X
}

Recibido: 26-05-2021

Aceptado: 25-06-2021

\section{Resumen}

El principal objetivo del artículo será contemplar y analizar escueta y globalmente el proceso de modernización de las Fuerzas Armadas en los últimos decenios del siglo XX, así como poner de relieve la obligada interdependencia entre aquel y el cambiante entorno político-social e internacional. A tal efecto, se prestará atención a los cuatro principales hitos del citado proceso: reorganización de la superestructura española de defensa; reforma de la organización y revisión de las funciones encomendadas a los ejércitos; inserción de España en los organismos defensivos occidentales, y homologación de la justicia militar con la ordinaria.

Palabras-clave: España, siglo XX, Transición y consolidación democráticas, Alianzas defensivas, Organización militar.

\footnotetext{
${ }^{1}$ (dunlyssa@telefonica.net). Coronel del Ejército retirado y Doctor en Historia por la UNED. Profesor del Programa de Doctorado en Seguridad Internacional y del Máster en Historia Militar de España del Instituto Universitario General Gutiérrez Mellado (UNED). Presidente de la Asociación Española de Historia Militar. Ha organizado ocho Congresos de Historia Militar. Obtuvo el Premio Ejército en 1974 y el Premio ISFAS en 2007. Entre sus publicaciones cabe mencionar los libros Gutiérrez Mellado y su tiempo (Alianza, 2019), Atlas de la Guerra Civil española: antecedentes, operaciones y secuelas militares (Síntesis, 2007) e Historia del ejército en España (Alianza, 2005). Es también autor de más de un centenar de artículos y capítulos de obras colectivas.
} 


\begin{abstract}
The main objective of the article will be to consider and analyze the process of modernization of the Armed Forces in the last decades of the twentieth century, as well as to highlight the obligatory interdependence between it and the changing political-social and international environment. To this end, attention will be paid to the four main milestones of this process: reorganization of the Spanish defence superstructure; reform of the organization of the armed forces and review of the functions entrusted to them; insertion of Spain into Western defensive alliances, and accommodation of the military justice to the common one.
\end{abstract}

Keywords: Spain, Twentieth Century, Democratic Transition, Consolidation of Democracy, Defence Alliances, Military Organization.

\title{
Introducción
}

Las acciones políticas desarrolladas en España en materia de seguridad y defensa desde el inicio de la Transición permitieron superar definitivamente el aislacionismo de los siglos precedentes y situar al país dentro del concierto internacional de naciones. Actualmente, España entiende y proyecta su seguridad en el marco de alianzas y organismos internacionales de defensa de los que estuvo mucho tiempo ausente, y a los que ha sido capaz de incorporarse con energía y decisión. Gracias a ello, su perfil internacional inspira confianza a la comunidad internacional y su compromiso con la seguridad y defensa de Occidente y con la paz mundial ha ido más allá de las tradicionales declaraciones programáticas del pasado.

Todo ello fue posible gracias a dos procesos simultáneos y culminados en un plazo de tiempo sorprendentemente breve, desde el punto de vista histórico, y ambos acometidos durante el reinado de Juan Carlos I (Puell 2017). De una parte, la transformación del diseño de la política de seguridad y defensa, sin duda alguna la más trascendental y sustancial de la historia reciente de España (Rodrigo 1995). Y de otra, la reforma y modernización de la estructura, organización y funciones de las Fuerzas Armadas (FAS), las cuales sufrieron un cambio de mucha mayor intensidad y profundidad que el producido en cualquier otra institución u organismo estatal, contribuyendo muy positivamente a normalizar la gobernabilidad del país y a eliminar para siempre el secular intervencionismo castrense (Ortega, 2008).

En la consecución de ambos procesos pueden distinguirse dos fases o etapas claramente definidas, aunque ligeramente solapadas entre sí. Durante la primera, de unos veinte años de duración y que convendremos en denominar 
"etapa de transición militar" (1976-1982), se desmantelaron las bases de la institución militar franquista y se definieron las líneas maestras de la que la sustituyó (Aguilar 2019). Durante la segunda, que llamaremos "etapa de consolidación" (1982-2001), iniciada cuando el Partido Socialista Obrero Español (PSOE) accedió por primera vez al gobierno, se terminó de perfilar el nuevo modelo, se definieron los objetivos de la política de defensa, se modificó la misión de las FAS, se reformó radicalmente su organización y se abolió el servicio militar obligatorio (Puell 2013; Serra 2008).

A efectos metodológicos, se prestará especial atención a los cuatro principales hitos de ambas etapas:

- Creación de la Junta de Jefes de Estado Mayor (JUJEM) y del Ministerio de Defensa.

- Inserción de las FAS en el texto constitucional de 1978 y preparación y promulgación de la Ley Orgánica de Criterios Básicos de la Defensa Nacional y la Organización Militar (LODOM) de 1980, modificada en 1984.

- Homologación y redefinición de la política de defensa y seguridad.

- Inserción de la jurisdicción militar en la jurisdicción ordinaria.

\section{Creación de la JUJEM y del Ministerio de Defensa}

El nacimiento del Ministerio de Defensa estuvo íntimamente ligado al largo proceso de gestación de la $\mathrm{LODOM}^{2}$. Es decir, el reducido elenco de militares reformistas de los años setenta del siglo XX pensaron primero en redactar lo que con el tiempo se transformaría en la actual Ley Orgánica de la Defensa Nacional ${ }^{3}$, que en unificar los Ministerios del Ejército, de Marina y del Aire, trilogía impuesta por el general Franco nada más terminar la Guerra Civil, durante la cual España se había adelantado al resto de los países occidentales con la creación de sendos Ministerios de Defensa Nacional en ambos bandos.

El general Gutiérrez Mellado, que sería el primero en desempeñar la cartera de Defensa, reconoció, nada más haber sido nombrado por Suárez vicepresidente primero del Gobierno para Asuntos de la Defensa en septiembre de 1976, que los militares sentían "la natural incertidumbre por el futuro", que

\footnotetext{
${ }^{2}$ La gestación del Ministerio de Defensa fue larga y accidentada. Los primeros pasos se dieron en 1968, nada más hacerse cargo de la dirección del CESEDEN el teniente general Manuel Díez-Alegría, y la primera vez que se contempló la posibilidad real de organizarlo surgió siete años después, en el Proyecto de Ley elaborado por el gabinete del primer vicepresidente del Gobierno para Asuntos de la Defensa, el teniente general Fernando de Santiago Díaz de Mendívil, poco después de morir Franco (Puell 2007).

${ }^{3}$ Ley Orgánica 5/2005 de 17 de noviembre, de la Defensa Nacional, Boletín Oficial del Estado (en notas sucesivas BOE) de 18 de noviembre de 2005.
} 
no mostraban "gran entusiasmo" por los cambios que se avecinaban y que entre sus más inmediatos colaboradores "predominaba la desorientación" en cuanto al alcance y objetivos de la inevitable e imprescindible reforma de la inadecuada estructura castrense heredada del franquismo. Y añadía que lo único que él tenía "muy claro" era la imperiosa necesidad de transformarla en un instrumento eficaz y operativo "con el menor coste posible", aunque sin poder guiarse por "ningún modelo concreto, ni español ni extranjero" (Gutiérrez 1983: 43 y 79).

A tal efecto, decidió no partir de cero sino transformar lo ya existente, en consonancia con la postura de que la transición fuese un proceso reformista y no rupturista con el pasado ${ }^{4}$. Es decir, el vicepresidente sustentó la reforma en la preexistente estructura de los tres departamentos ministeriales, que iban a desaparecer, y en la del Alto Estado Mayor (AEM), único organismo que por estar contemplado en el ordenamiento constitucional franquista -la Ley Orgánica del Estado de 1967 (LOE)-, era obligado mantener ${ }^{5}$. El primer paso fue, en base a lo ya vigente en la Armada ${ }^{6}$, atribuir el mando operativo de los Ejércitos de Tierra y del Aire a sus respectivos jefes de Estado Mayor ${ }^{7}$. Inmediatamente después, se les agrupó en la Junta de Jefes de Estado Mayor (JUJEM), ya contemplada en los proyectos de Díez-Alegría, cuya presidencia se atribuyó al jefe del AEM. A partir de ese momento, y hasta las modificaciones introducidas por Narcís Serra en 1984, la JUJEM pasó a ejercer el mando colegiado de la fuerza como cúspide de lo que empezó a denominarse "cadena de mando"s.

Una vez segregadas las competencias operativas de las administrativas, bastaba con confiar estas a un único departamento ministerial que, para

4 "Comisión de Defensa del Congreso de los Diputados. Sesión n. ${ }^{\circ} 1$ (informativa), celebrada el martes 10 de enero de 1978”, Ejército, 459 (1978), pp. 5-6.

${ }^{5}$ El título VI de la LOE contenía tres artículos cuya posterior incidencia sobre la Constitución de 1978 aconseja transcribir: “Art. 37. Las Fuerzas Armadas de la Nación, constituidas por los Ejércitos de Tierra, Mar y Aire y las Fuerzas de Orden Público, garantizan la unidad e independencia de la Patria, la integridad de sus territorios, la seguridad nacional y la defensa del orden institucional. Art. 38. Una Junta de Defensa Nacional, integrada por el Presidente del Gobierno, los Ministros de los Departamentos militares, el Jefe del Alto Estado Mayor y los Jefes de Estado Mayor de los Ejércitos de Tierra, Mar y Aire, propondrá al gobierno las líneas generales concernientes a la seguridad y defensa nacional. A esta Junta de Defensa Nacional podrán ser incorporados los Ministros o Altos Cargos que, por el carácter de los asuntos a tratar, se considere conveniente. Art. 39. Un Alto Estado Mayor, dependiente del Presidente del Gobierno, será el órgano técnico de la Defensa Nacional, con la misión de coordinar la acción de los Estados Mayores de los tres Ejércitos". Ley Orgánica del Estado núm. 1/1967, de 10 de enero, BOE de 11 de enero de 1967.

${ }^{6}$ Desde 1970, el mando operativo sobre las unidades navales era ejercido por el jefe de Estado Mayor de la Armada: Ley 9/1970, de 4 de julio, Orgánica de la Armada, BOE de 7 de julio de 1970.

${ }^{7}$ Real Decreto 3026/1976, de 23 de diciembre y Real Decreto-Ley 9/1977, de 8 de febrero, por los que, respectivamente, se regulan las atribuciones, funciones y responsabilidades del Jefe de Estado Mayor del Ejército y del Jefe de Estado Mayor del Aire, BOE de 11 de enero y de 11 de febrero de 1977.

8 Real Decreto-Ley 11/1977, de 8 de febrero, por el que se institucionaliza la Junta de Jefes de Estado Mayor y se regulan sus atribuciones, funciones y responsabilidades, BOE de 9 de febrero de 1977. 
comenzar su andar, contaría con tres Secretarías Generales, una para cada ejército. Este fue el esquema presentado al presidente Suárez a comienzos de 1977, cuya ejecución se demoró hasta julio de ese año, después de celebradas las primeras elecciones generales ${ }^{9}$.

Durante aquel verano y en el breve plazo de cuatro meses, se desarrolló el organigrama del flamante Ministerio, que vio la luz el 2 de noviembre ${ }^{10}$. Éste era sumamente sencillo: una Subsecretaría, una Dirección General de Armamento, una oficina de prensa y un centro de inteligencia-el CESID- para agrupar a los servicios dependientes de la Presidencia del Gobierno y del AEM. La Subsecretaría de Defensa, verdadero núcleo del nuevo departamento, se nutrió con el personal e infraestructura procedentes de las abolidas Secretarías Generales de los Ejércitos y articuló cuatro dependencias, equiparadas a direcciones generales e inspiradas en las secciones tradicionales de cualquier Estado Mayor: Secretaría General de Personal (SEGENPER), Secretaría General Técnica (SEGENTE), Secretaría General de Política de Defensa (SEGENPOL) y Secretaría General de Asuntos Económicos (SEGENECO) (Puell 2007 ).

El evidente dualismo creado entre el nuevo órgano de gestión y la cadena de mando enseguida suscitó conflictos corporativos en el seno de las FAS, esgrimidos desde la ultraderecha para erosionar el proceso de democratización de las estructuras estatales. La premisa era que la cadena de mando no dependía del Gobierno -posición asumida por una gran mayoría de militares-, sino directamente del rey, mando supremo de las FAS conforme a la LOE. El Ministerio, es decir, el órgano gestor, se presentaba como un departamento civil totalmente ajeno al universo castrense (Puell 2019: 360). Este planteamiento, machaconamente aireado por la prensa ultraderechista, llegó a incitar a muchos cuadros de mando a sumarse al golpe de Estado del 23 de febrero de 1981, que, al decir de quienes lo tramaron, había sido impulsado y autorizado por el propio monarca (Medina 2004: 403).

Puede concluirse, pues, que Gutiérrez Mellado no quiso o no llegó a plantearse romper con la tradición histórico-jurídica de los ejércitos como institución autónoma. Por el contrario, la letra y el fondo del Real Decreto que definió la estructura orgánica del Ministerio de Defensa, en lugar de precisar con claridad la relación FAS-Poder Ejecutivo, dejaban traslucir la voluntad política de evitar que se rompiese el estrecho vínculo, creado por Cánovas y reforzado durante el franquismo, entre los ejércitos y la Jefatura del Estado respecto al mando y a la organización de las FAS, confiando en que la condición militar y el prestigio personal de Gutiérrez Mellado, recién nombrado ministro de

\footnotetext{
${ }^{9}$ Real Decreto 1558/1977, de 4 de julio, por el que se reestructuran determinados órganos de la Administración General del Estado, BOE de 5 de julio de 1977.

${ }^{10}$ Real Decreto 2723/1977 de 2 de noviembre, por el que se estructura orgánica y funcionalmente el Ministerio de Defensa, BOE de 5 de noviembre de 1977.
} 
Defensa, encauzara y resolviera los problemas que pudieran suscitarse. Varias son las peculiaridades que, a este respecto, quedaban patentes en el citado Real Decreto:

- Coexistencia de dos ámbitos de actuación diferenciados. Uno, militar, encabezado por la JUJEM e integrado por los jefes de Estado Mayor, sus cuarteles generales y las fuerzas a sus órdenes y regulado por su propia normativa, tanto en lo operativo como en ciertas competencias administrativas. Y otro, político, materializado en la estructura ministerial, cuya única función era proporcionar recursos a los ejércitos.

- Segregación de la actividad política y la militar. Según este esquema, el ministro de Defensa carecía de papel y competencias directas sobre la fuerza, y la estructura ministerial debía limitarse a financiarla y a dotarla de medios humanos y materiales.

- Autonomía de las FAS respecto a la Administración General del Estado (AGE), quedando inmersas en una especie de limbo de difícil encaje legal y ajeno al Gobierno, situación que Suárez y Gutiérrez Mellado optaron por mantener, de forma que la política militar quedase totalmente en manos de los militares.

Otro llamativo y peculiar rasgo de la flamante estructura ministerial fue su acusado talante jerárquico y corporativo, trasunto fiel de la cultura castrense tradicional. Incluso su organigrama y nomenclatura se diferenciaba de lo habitual en los demás departamentos. Cada uno de los altos cargos debía ser desempeñado por un militar de carrera, precisando hasta su empleo y situación administrativa. Los restantes puestos de trabajo, desde el nivel de subdirector general al de auxiliar administrativo, debían también proveerse por personal militar en activo y distribuirse matemáticamente entre los tres ejércitos, asignándose un tercio de las vacantes a cada uno de ellos.

Agustín Rodríguez Sahagún, nombrado por Suárez ministro de Defensa en 1979 -vano intento dirigido a salvaguardar a Gutiérrez Mellado de los furibundos ataques de la ultraderecha-, se sintió muy incómodo al no poder elegir libremente a sus colaboradores, pero no se atrevió a rectificar aquel encorsetado esquema. Sin embargo, su sucesor, Alberto Oliart, nombrado por Calvo-Sotelo en febrero de 1981, se vio forzado a hacerlo para afrontar tres problemas puntuales (Olmo 2007: 314):

1. La decisión de reorganizar y potenciar el CESID después del 23-F. Para ello y, tras acordar con Calvo-Sotelo poner a su frente al entonces 
teniente coronel Emilio Alonso Manglano, fue previamente preciso modificar el Real Decreto de 1977 que asignaba el puesto a un general.

2. La imperiosa necesidad de poner término a los enfrentamientos que, en el seno de la JUJEM, se suscitaban a la hora de distribuir el presupuesto ministerial entre los tres ejércitos. En 1980 se había llegado al extremo de que, por no ponerse de acuerdo los respectivos jefes de Estado Mayor, no pudieron asignarse determinadas partidas. Para solventar la situación, Oliart decidió sustituir por un civil al general del Cuerpo de Intendencia que, conforme a lo previsto en 1977, estaba al frente de la SEGENECO, incapaz, debido a su menor rango, de hacer entrar en razón a los cuatro tenientes generales que integraban la JUJEM.

3. Similares trabas y problemas aconsejaron confiar también a un civil la Subsecretaría de Defensa.

Habría, sin embargo, que esperar a 1984 para que aquel elemental y escasamente operativo Ministerio empezara a convertirse en un instrumento potente y homologable con sus homónimos occidentales, útil para dirigir la política de seguridad y defensa del Estado y neutralizar las apetencias de la cadena de mando por mantener la autonomía de las FAS. Efectivamente, en paralelo a la reforma de la Ley de Bases de la Defensa, de la que después se hablará, Narcís Serra lo reestructuró en tres grandes áreas, reservándose para sí mismo la gestión del Cuerpo de la Guardia Civil, en su vertiente militar, y el control del CESID ${ }^{11}$ :

1. Una de estricto carácter militar, configurada por el Ejército de Tierra, la Armada y el Ejército del Aire y dependiente de un mando unipersonal, para reemplazar al colegiado de la JUJEM: el jefe de Estado de la Defensa (JEMAD), "principal colaborador del Ministro en el planeamiento y ejecución de los aspectos operativos de la política militar".

2. Otra de gestión de medios, dirigida por el secretario de Estado de Defensa, "principal colaborador del ministro en los asuntos relativos a la gestión y control de los recursos económicos, la política de armamento y material, y la de infraestructura de la Defensa".

3. Y una tercera, coordinada por el subsecretario de Defensa, "principal colaborador del Ministro en la dirección de la política de personal y en la responsabilidad del régimen interior del Ministerio".

${ }^{11}$ Real Decreto 135/1984, de 25 de enero, por el que se reestructura el Ministerio de Defensa, BOE de 1 de febrero de 1984. 
El aspecto más trascendental y sustancial de esta reforma, aparte, tal vez, de no exigirse que los altos cargos del Ministerio fueran desempeñados por militares, era que las FAS quedaban directamente subordinadas al ministro de Defensa y embebidas en el organigrama ministerial, lo que suponía que, por primera vez en la historia, pasaban de hecho y de derecho a formar parte de la AGE y perdían su capacidad de autogobernarse y de codearse con los demás poderes en pie de igualdad.

Para incidir en la misma línea se estableció una dependencia funcional entre las recién creadas direcciones generales del Ministerio y los correspondientes organismos existentes en los cuarteles generales, al objeto de "formular una política común y una gestión coordinada de los tres Ejércitos". Este último principio fue el más arduo de aplicar, dada la resistencia ofrecida por los cuarteles generales, lo que obligó a volver a insistir en ello en 1987 y precisar la citada vinculación caso por caso ${ }^{12}$. Y, de nuevo en 1989, cuando se desarrolló la estructura básica de los ejércitos, para concretar en detalle, mediante tres disposiciones adicionales, la dependencia funcional de cada uno de los organismos administrativos y gestores dependientes de los jefes de Estado Mayor $^{13}$.

\section{Inserción de las FAS en la Constitución}

Uno de los primeros borradores del texto constitucional, filtrado por la revista Cuadernos para el Diálogo a los principales diarios nacionales el 22 de noviembre de 1977, reproducía los trabajos preparatorios elaborados por la ponencia hasta aquel momento ${ }^{14}$. En él, el artículo 123 regulaba las relaciones entre el Estado y las FAS. Este artículo estaba inserto en el título sin numerar "Fuerzas Armadas, de Orden Público y estados de excepción", ubicado a continuación del referido al Gobierno, al que el artículo 94 ya confería las competencias que después pasaron al $97^{15}$. Poco después, el 5 de enero de 1978, el Boletín Oficial de las Cortes Españolas publicó el anteproyecto del texto constitucional, en el que la referencia a las FAS se había trasladado al artículo 10 del Título Preliminar, lo que las anteponía e independizaba del resto de poderes del Estado, especialmente, del ejecutivo.

\footnotetext{
12 Real Decreto 1/1987, de 1 de enero, por el que se determina la Estructura Orgánica Básica del Ministerio de Defensa, BOE de 2 de enero de 1987.

13 Real Decreto 1207/1989, de 6 de octubre, por el que se desarrolla la estructura básica de los Ejércitos, BOE de 11 de octubre de 1989.

${ }^{14}$ De entre los varios borradores filtrados en aquellos meses, este fue el único validado por uno de ponentes constitucionales, quien testimonió que se ajustaba exactamente a lo esbozado en los trabajos preparatorios (Fraga 1978).

15 "El Gobierno dirige la política interior y exterior, la Administración civil y militar y la defensa del Estado".
} 
La primera ubicación prevista en el borrador incardinaba a las FAS en la función ejecutiva y administrativa, y las subordinaba al Gobierno. En cambio, su inserción en el Título Preliminar, en pie de igualdad con las líneas maestras del Estado de Derecho - carácter social y democrático, soberanía popular, forma de Estado, unidad nacional y régimen autonómico, lengua, símbolos nacionales y capitalidad- e inmediatamente después de hacer referencia a los partidos políticos y a los sindicatos -instituciones constitucionalmente relevantes y dotadas de plena autonomía respecto al Estado y al Gobierno-, presuponía consolidar de iure el singular régimen jurídico que las había caracterizado desde el último cuarto del siglo XIX.

No ha trascendido hasta el momento por qué se hizo así $\mathrm{y}$, pese a lo mucho que se ha especulado al respecto, las verdaderas razones del cambio de ubicación entran en el terreno de las hipótesis (Serra 2008: 138-139). Una de las más barajadas lo atribuyó al empeño de Gutiérrez Mellado por mantener a los ejércitos al margen de la lucha entre partidos, en línea con otra de sus más sonadas decisiones: obligar a solicitar el retiro a los militares que optasen por participar activamente en política -algo bastante habitual hasta entonces- ${ }^{-}$ sancionar con dureza a quienes contraviniesen tal norma ${ }^{16}$.

El caso fue que, en el texto definitivo, aprobado por las Cortes el 31 de octubre de 1978 y refrendado por el pueblo español el 6 de diciembre de ese año, las FAS fueron contempladas en el artículo octavo del Título Preliminar, lo que parecía dejarlas al margen del Poder Ejecutivo ${ }^{17}$. Ello daría pie a todo tipo de interpretaciones, unas interesadas y otras aventuradas, respecto al ejercicio de las misiones que el mismo artículo atribuía a las FAS y, sobre todo, en relación a su aparente autonomía y capacidad para decidir, con criterios propios e independientes, cuándo, dónde y cómo ejercerlas.

Y la cosa pudo todavía ser más grave, pues una posterior redacción del artículo 123, que no llegó a filtrarse a la prensa, refundía en su inciso 2 el contenido, debidamente actualizado, de los artículos 38 y 39 de la LOE, al igual que el artículo 37 había servido de referencia para redactar el inciso 1.

2. Una ley orgánica regulará los principios básicos de la Organización Militar dentro de los de la presente Constitución y la composición y funciones de una Junta Superior, como órgano asesor del Gobierno en asuntos relativos a la Defensa, así como de una Junta de Jefes de Estado Mayor, como órgano colegiado superior del mando militar de las Fuerzas Armadas.

\footnotetext{
${ }^{16}$ Real Decreto-Ley 10/1977, de 8 de febrero, por el que se regula el ejercicio de actividades políticas y sindicales a los componentes de las Fuerzas Armadas, BOE de 9 de febrero de 1977.

17 “1. Las Fuerzas Armadas, constituidas por el Ejército de Tierra, la Armada y el Ejército del Aire, tienen como misión garantizar la soberanía e independencia de España, defender su integridad territorial y el ordenamiento constitucional. 2. Una ley orgánica regulará las bases de la organización militar, conforme a los principios de la presente Constitución”.
} 
Afortunadamente, el 14 de noviembre de 1977, Gutiérrez Mellado, nada más tener conocimiento de aquella redacción, comunicó a Suárez que consideraba sumamente desafortunado el espaldarazo que la Constitución iba a dar a la JUJEM y que consideraba más adecuado que los órganos superiores de la defensa se regularan por Ley, al igual que el resto de los que conformaban la AGE. Gracias a su intervención, realmente decisiva para que el artículo octavo se redactara en la forma que finalmente adoptó, fue posible plantear y llevar a buen término la trascendental reforma patrocinada por Narcís Serra seis años más tarde, cuyo principal logro, como antes se ha apuntado, fue subordinar las FAS al Poder Ejecutivo y poner término a su tradicional autonomía funcional (Serra 2008: 140).

\section{La LODOM de 1980 y su reforma en 1984}

Las erróneas, y en muchos casos interesadas, interpretaciones derivadas de la inserción de las FAS en el Título Preliminar de la Constitución terminaron contaminando algunos aspectos esenciales de la normativa que regularía su articulación en la AGE y sus relaciones con la Corona y con el Gobierno.

La primera de las tres sucesivas normas promulgadas, aprobada por las Cortes el 28 de diciembre de 1978, al día siguiente del solemne pleno en que el rey Juan Carlos sancionó la Constitución, había sido redactada por el equipo de militares que trabajaban con Gutiérrez Mellado y, en lo esencial, se basaba en el Proyecto de Ley Orgánica de la Defensa elaborado por Díez-Alegría en 1974 (Puell 2007: 297-303). Podría decirse que la Ley de diciembre de 1978 nació con vocación de interinidad y para intentar encarrilar las cada vez más complejas relaciones entre el Ministerio de Defensa y la JUJEM, que, al postularse como heredera del AEM, se consideraba directamente dependiente del presidente del Gobierno, conforme a lo previsto en la LOE. Debido a ello, aquella Ley atribuyó al ministro determinadas funciones "por delegación del Presidente del Gobierno", aunque escasamente definidas, y concretó con bastante más detalle las de la Junta de Defensa Nacional (JDN) y de la JUJEM ${ }^{18}$.

La segunda de las normas, la LODOM, obedecía al mandato explícito del artículo octavo de la Constitución y fue también redactada por militares, en esta ocasión por los miembros del gabinete del primer ministro civil de la democracia, Agustín Rodríguez Sahagún ${ }^{19}$. Lamentablemente, su debate en las Cortes coincidió en el tiempo con uno de los periodos más críticos en materia de terrorismo e inestabilidad política y social, razón por la cual la UCD impuso su

\footnotetext{
18 Ley 83/1978, de 28 de diciembre, por la que se regulan las funciones de distintos Órganos Superiores del Estado en relación con la Defensa Nacional, BOE de 12 de enero de 1979.

${ }_{19}$ Proyecto de Ley Orgánica por la que se regulan las Bases de la Defensa Nacional y la Organización Militar, Boletín Oficial de las Cortes Generales, serie A, n. ${ }^{\circ}$ 72-I, de 21 de septiembre de 1979.
} 
mayoría parlamentaria y optó por conservar los principios que tradicionalmente habían regido en España las relaciones del Estado con las FAS ${ }^{20}$.

Consecuencia directa de tal opción y de tan adversa coyuntura fue la determinación de situar, en línea prácticamente horizontal, bajo la autoridad del rey, mando supremo de las FAS según el artículo 62.h de la Constitución, al presidente del Gobierno, al ministro de Defensa y a la JUJEM, sin hacer referencia alguna a que los ejércitos dependían del Poder Ejecutivo en cualquier Estado de Derecho. Aunque sin duda Suárez y Gutiérrez Mellado obraron de buena fe, incurrieron en el grave error de creer que el reconocimiento de la autonomía de las FAS ayudaría a mitigar el malestar de los militares, sin llegar a advertir que aquella relación de dependencia daba alas a los nostálgicos del franquismo.

Según el detallado análisis efectuado por el general del Olmo, las tres principales instituciones afectadas - la Corona, el Gobierno y las FAS- se esforzaron por dar una salida airosa a su atípica relación en un Estado de Derecho, e intentaron articularla de la mejor forma posible (Olmo 2007: 317 319). No obstante, aquella Ley también presentaba algunas novedades bastante positivas, entre las que cabe destacar la atribución de más funciones gestoras al ministro, la inclusión de la JUJEM en el organigrama ministerial, aunque solo fuese "a efectos administrativos", y la introducción del Poder Legislativo en el ámbito de la defensa, por primera vez en la historia y gracias a la enmienda presentada por el Grupo Parlamentario de Coalición Democrática en el Congreso de los Diputados (Ley s. a.: 9, 70-71, 100 y 110).

El revulsivo que supuso el frustrado golpe de Estado del 23 de febrero de 1981 forzó a reconsiderar la relación establecida entra las FAS y la AGE y a acabar de modo definitivo con su resistencia a establecer lazos de dependencia con el Poder Ejecutivo. Pero primero era imprescindible interpretar, congruente e integradamente, el sistema jurídico de poderes, instituciones y relaciones establecido por la Constitución y, si este los avalaba, establecer unos fundamentos de derecho distintos de los que sustentaron la LODOM.

A ese objeto, el ministro Oliart, una vez resuelto satisfactoriamente el proceso penal contra los golpistas a mediados de 1982, constituyó un pequeño grupo de trabajo integrado por Luis Sánchez Agesta, catedrático de Derecho Constitucional, el teniente coronel de Aviación Ramón Fernández Sequeiros y el comandante auditor Jesús del Olmo. Tras debatir varios meses, el grupo concluyó que la Constitución no legitimaba en absoluto la autonomía de la institución militar, a consecuencia de lo cual era posible derogar toda la normativa que sustentaba tal presunción, partiendo de la todavía vigente Ley Constitutiva del Ejército de 1878 (Puell 2005: 112-114). También establecieron

${ }^{20}$ Ley Orgánica 6/1980, de 1 de julio, por la que se regulan los criterios básicos de la defensa nacional y la organización militar, BOE de 10 de julio de 1980.

Araucaria. Revista Iberoamericana de Filosofí, Política, Humanidades y Relaciones Internacionales, año $23, \mathrm{n}^{\circ} 47$. Segundo cuatrimestre de 2021. Pp. 403-430. ISSN 1575-6823 e-ISSN 2340-2199 https://dx.doi.org/10.12795/araucaria.2021.i47.18 
una serie de premisas para interpretar los aspectos más conflictivos del texto constitucional, entre las que cabría destacar (Olmo 2007: 321-326):

- El artículo octavo iba dirigido a contemplar la necesaria defensa del Estado y de sus ciudadanos, encomendada a los ejércitos como organización permanente, para articular e integrar a los ciudadanos en caso de conflicto.

- Al tener todos los españoles "el derecho y el deber de defender a España” (art. 30), las misiones definidas en el artículo octavo afectaban a la sociedad en su conjunto y no solo a quienes, en un momento concreto, integraban los ejércitos. La activación de dichas misiones estaba sujeta a los procedimientos previstos por la Constitución (arts. 63.3 y 116).

- El mando supremo de las FAS atribuido al rey no podía ejercerse al margen de la Constitución, que negaba la existencia de una línea jerárquica de mando exenta del refrendo gubernamental (arts. 56.3 y 64).

- $\quad$ El Gobierno era el único responsable de la defensa del Estado (art. 97).

- El ejercicio de la jurisdicción militar debía ceñirse al ámbito estrictamente castrense y estaba sujeto al principio de unidad jurisdiccional del Estado (art. 117.5).

El adverso resultado en las elecciones de octubre de 1982 impidió que el Gobierno de Calvo-Sotelo llegase a plantearse la reforma de la LODOM y Oliart transfirió las conclusiones del grupo de trabajo a Serra, quien, tras estudiarlas y analizar en profundidad cómo se articulaba la organización de la defensa en otros países europeos, remitió a las Cortes un Proyecto de Ley orientado a modificar las funciones y competencias atribuidas a los principales organismos vinculados con la defensa, que publicó el Boletín Oficial de las Cortes Generales el 28 de octubre de 1983. El trámite parlamentario se realizó por el procedimiento de urgencia y ni el Congreso de los Diputados ni el Senado introdujeron enmiendas de importancia en el texto remitido por el Gobierno. El 31 de diciembre de 1983 la Ley fue definitivamente aprobada y recibió la sanción regia el 5 de enero de $1984^{21}$. Sus principales novedades eran (Serra 2008: 191-192):

1. El presidente del Gobierno pasaba a ejercer el mando directo y efectivo de las FAS, sin ningún tipo de ambigüedad, y lo delegaba en

${ }^{21}$ Ley Orgánica 1/1984, de 5 de enero, de reforma de la ley orgánica 6/1980, de 1 de julio, por la que se regulan los criterios básicos de la defensa nacional y la organización militar, BOE de 7 de enero de 1984. 
el ministro de Defensa quien, a su vez, era el responsable último del mantenimiento de la disciplina en los ejércitos.

2. La JDN, contemplada como instancia asesora y consultiva del rey y del presidente del Gobierno, dejaba de tener funciones ejecutivas.

3. El JEMAD, figura de nueva creación, dependía orgánica y funcionalmente del ministro de Defensa, que delegaba en él la supervisión del estado de adiestramiento y eficacia de las tropas. En caso de guerra sería nombrado jefe del Mando Operativo de las FAS.

4. La JUJEM se convertía en órgano asesor y consultivo del Gobierno y del ministro de Defensa y perdía su condición de órgano superior de la cadena de mando militar.

5. Los Consejos Superiores del Ejército, de la Armada y del Ejército del Aire, integrados por los tenientes generales y almirantes en activo, se transformaban también en órganos consultivos y perdían sus anteriores competencias en cuestiones de personal, en particular las de que exigían su visto bueno para el ascenso y destino de los oficiales generales, y para el ascenso de los coroneles y capitanes de navío al generalato.

\section{Política de defensa y seguridad}

La redefinición de la política exterior española presenta tres fases sucesivas y muy definidas: una primera fase de normalización y homologación internacional de la naciente democracia (1975-1982); una segunda fase de definición de sus líneas maestras (1982-1986); y una tercera fase, en la que se perfiló definitivamente el modelo diseñado (1986-1991) (Arenal 1992). Durante las tres, una de las cuestiones más cruciales, excepción hecha del largo y arduo proceso que condujo al ingreso en las Comunidades Europeas (CE) en 1985, fue el esfuerzo realizado para reconducir la política española de seguridad y defensa y homologarla con la del resto de países occidentales, cuestión esencial para la modernización de las FAS, sobre la que incidió muy positivamente, y a consecuencia de ello, sobre la gobernabilidad del país.

Tres eran también los asuntos que había que abordar en esta materia: modificar la descompensada relación bilateral con Estados Unidos (EEUU); contemplar la conveniencia de solicitar el ingreso en la Alianza Atlántica (OTAN), y establecer lazos con las organizaciones defensivas europeas, en particular con la Unión Europea Occidental (UEO). 


\subsection{Fase de normalización y homologación (1975-1982)}

\subsubsection{Homologación de la relación bilateral con EEUU (1975-1976)}

El Gobierno de Carlos Arias Navarro, herencia del franquismo que el rey Juan Carlos decidió prorrogar durante siete meses, y el primero de Adolfo Suárez no consideraron prioritaria la política exterior y la supeditaron al cambio político interno. No obstante, en enero de 1976, José María de Areilza, ministro de Asuntos Exteriores de Arias, con la anuencia del secretario de Estado estadounidense Henry Kissinger y el firme respaldo del rey, logró elevar de rango el humillante Acuerdo Ejecutivo que, desde 1953, regía la relación defensiva entre ambos países y el alquiler de instalaciones navales y aéreas en suelo español, sin que ello supusiera ningún compromiso firme en materia de seguridad, pese al riesgo derivado del almacenamiento de armas nucleares en la base de Rota, muy cercana a Cádiz.

El nuevo Tratado de Amistad y Cooperación, de marcado carácter político y ratificado por las Cortes Españolas y el Senado de Washington, normalizó en cierto sentido la relación, al incidir en la progresiva retirada del armamento nuclear e incluir una cláusula que reconocía la existencia de intereses comunes en el ámbito de la defensa ${ }^{22}$.

El Tratado de 1976 también contenía un artículo que evidenciaba la voluntad política del Gobierno español de adherirse a la OTAN en un futuro no muy lejano. A ese objeto, se contemplaba la creación de una Comisión de Coordinación, no solo entre las FAS españolas y estadounidenses, como hasta entonces, sino también con "otras fuerzas dedicadas a la defensa del Atlántico Norte", cuyo nombre definitivo fue bastante más explícito: Comisión ad hoc para la coordinación con la OTAN. Por esta vía se obtuvo información que resultaría sumamente útil a la hora de producirse el ingreso en 1982, ya que, desde 1978, una delegación estadounidense se desplazaba a Madrid para dar cuenta de lo tratado en las reuniones del Comité de Planes de Defensa y del Consejo Atlántico (Martínez-Esparza 1989: 429).

\subsubsection{Ingreso en la Alianza Atlántica (1977-1982)}

Marcelino Oreja, nombrado ministro de Asuntos Exteriores por Suárez en julio de 1976, consideraba que la incorporación de España a la OTAN era la fórmula más idónea para normalizar las relaciones con el bloque occidental, y

\footnotetext{
${ }^{22}$ Instrumento de ratificación de España del Tratado de Amistad y Cooperación entre España y los Estados Unidos de América, los siete Acuerdos Complementarios al mismo y ocho Canjes de Notas de 24 de enero de 1976 y del acuerdo de desarrollo del Tratado de Amistad y Cooperación, los Anexos de Procedimiento I, II, III, IV, V, VI, VII, VIII, IX-a, IX-b, X, XIII, XIV, XV, XVI y dos Canjes de Notas de 31 de enero de 1976. BOE de 6 de noviembre de 1976.
} 
poder así reemplazar la impopular relación bilateral con EEUU por una relación multilateral más equilibrada. Sus gestiones lograron que, el 17 de noviembre de 1976, la Asamblea Parlamentaria de la OTAN aprobase una resolución favorable a la incorporación española, con lo que desapareció el veto que la había cortocircuitado desde 1949 (Portero 2000: 477).

Sin embargo, la radical oposición de los principales partidos de izquierdas, entonces todavía ilegales, indujo al primer Gobierno de Suárez a mantener una postura cauta, aunque ambigua, sobre el tema. La declaración programática de su segundo Gobierno, el surgido de las primeras elecciones generales (15 de junio de 1977), se limitó a prometer "la apertura de un debate con los representantes del pueblo legítimamente elegidos", pero Oreja, al desplazarse a Bruselas inmediatamente después para solicitar el ingreso en las CE, aprovechó para entrevistarse con el secretario general de la OTAN y nombró embajador en la capital belga a un decidido atlantista (Powell 2000: 432).

La indefinición, mantenida durante los cuatro años que Suárez permaneció al frente del ejecutivo, terminó nada más entrar Calvo-Sotelo en escena. En su discurso de investidura, pronunciado tres días antes del golpe de Estado, anunció su propósito de articular una mayoría parlamentaria que permitiese solicitar el ingreso y, en agosto de 1981, formalizó ante las Cortes la solicitud, que fue aprobada el 29 de octubre en el Congreso de los Diputados por 186 votos a favor y 146 en contra, tras un largo y durísimo debate. Un mes después, superado también el trámite ante el Senado, por 106 votos a favor y 60 en contra, se presentó la solicitud de ingreso en Bruselas y, el 10 de diciembre, los ministros aliados la aceptaron. E1 28 de mayo de 1982 finalizó el largo proceso de ratificación; al día siguiente, España se convirtió en el decimosexto miembro de la OTAN y, el 10 de junio de 1982, el ministro de Asuntos Exteriores, José Pedro Pérez Llorca, y el de Defensa, Alberto Oliart, participaron por primera vez de pleno derecho en la cumbre de Bonn.

Al hilo del proceso anterior, se venía negociando la renovación del Tratado firmado con EEUU en enero de 1976 y que había llegado a su término al cabo de cinco años. Evidentemente, el inminente ingreso en la OTAN permitió modificar en profundidad el carácter de esta relación y favoreció que, el 2 de julio de 1982, se firmase un Convenio de Amistad, Defensa y Cooperación, que ya consideraba la cooperación bilateral en el marco de la Alianza Atlántica. Su aspecto más novedoso fue delimitar el empleo de las llamadas "instalaciones de apoyo" e introducir unas "autorizaciones de uso" para hacerlo. Lo primero hacía referencia a todo "terreno, construcción o conjunto de ellos", propiedad del Estado español, en el que se admitía la presencia y actividades de las FAS estadounidenses para las finalidades específicas del Convenio. Y lo segundo, a los permisos necesarios para utilizar el espacio aéreo, las aguas y los territorios españoles, así como polígonos de tiro, oleoductos, etc. Todo ello a cambio de 
la apertura de líneas de crédito para adquirir material militar, bienes de equipo, becas académicas, etc. (Calvo 1993: 16-17).

\subsection{Fase de definición de la política de defensa (1982-1986)}

Los partidos políticos contrarios al ingreso español en la OTAN, y en particular el PSOE, interpretaron que la decisión de Calvo-Sotelo era un acto precipitado y desleal, que hurtaba a la opinión pública el gran debate sobre la cuestión que venían anunciando los gobiernos de UCD desde 1977 y le exigieron un referéndum consultivo (Resoluciones 1981). Convocadas las elecciones de octubre de 1982, el programa del PSOE proclamaba que, en caso de llegar al poder, se interrumpirían las negociaciones en curso y se convocaría el citado referéndum:

En la línea ya expresada anteriormente por el PSOE, en un primer momento y como medida inmediata, se congelarán las negociaciones para la integración en la organización militar. En un segundo momento, se mantendrá el compromiso contraído por el PSOE de convocar un referéndum para que sea el pueblo español el que decida acerca de nuestra permanencia en la OTAN (Por el cambio 1982: 47).

El triunfo del PSOE en las urnas fue realmente aplastante -202 escaños de los 350 que componían el Congreso de los Diputados-, pero Felipe González se percató enseguida de que su pretensión de consolidar la democracia y modernizar el país exigía un contexto internacional favorable y la plena inserción de España en el bloque occidental, lo que requeriría no solo ingresar en las CE, sino también permanecer en la OTAN (Portero 2000: 489). Ambos objetivos condicionaron la política exterior de su primer Gobierno. Aunque el 30 de noviembre de 1982, en su pragmático discurso de investidura, pasó sobre la cuestión como de puntillas, se mantuvo leal a las promesas electorales y, nada más tomar posesión ordenó congelar las arduas y complejas negociaciones para la incorporación a la estructura militar integrada, ya bastante adelantadas (Sánchez 1989).

A lo largo de 1983 continuó habiendo dudas en el seno del Partido y del Gobierno sobre lo que convenía hacer, pero las posturas favorables a la permanencia en la OTAN fueron ganando terreno al año siguiente. Además, el ministro de Defensa, Narcís Serra, logró hacer comprender a sus compañeros de Gobierno y de Partido que, para llevar a buen fin la ambiciosa reforma de las FAS que tenía entre manos, resultaría muy útil proporcionar a los militares un referente exterior difícilmente cuestionable por la oficialidad, tal como también había advertido Alberto Oliart (Serra 2008: 237-238). 
Todo ello se plasmó en el plan que Felipe González desarrolló ante el Congreso de los Diputados el 23 de octubre de 1984, con ocasión del primer Debate del Estado de la Nación, comprometiéndose también a convocar un referéndum ad hoc en 1986. El plan pretendía que todos los grupos parlamentarios respaldasen la política de paz y seguridad y constaba de diez puntos, por lo que la prensa lo llamó "Decálogo" y como tal ha pasado a la historia:

1. Permanencia de España en la Alianza Atlántica.

2. No incorporación a la estructura militar integrada de la OTAN.

3. Veto al armamento nuclear en el espacio español.

4. Reducción de la presencia militar estadounidense.

5. Ratificación del Tratado de Prohibición de Pruebas Nucleares.

6. Incorporación a la UEO.

7. Reivindicación de la soberanía sobre Gibraltar.

8. Participación activa en la Conferencia Europea de Desarme.

9. Firma de convenios defensivos bilaterales con los países europeos.

10. Consenso parlamentario en materia de política de defensa.

Aunque no sin cierta resistencia, el Decálogo se incluyó entre las resoluciones finales del XXX Congreso del PSOE, celebrado en diciembre de 1984, pero el resto de partidos se mostraron reacios a consensuar la política de defensa. Finalmente, el Gobierno logró que la minoría catalana presentase una moción a favor de la permanencia en la Alianza, que fue aprobada en diciembre de 1985 , lo que dio pie a poder pedir al pueblo español que refrendase los cuatro primeros puntos del Decálogo. Tras una enconada campaña, el referéndum se celebró el 12 de marzo de 1986, con escasa afluencia de votantes y un resultado muy ajustado: 59,42 por ciento de participación; 52,49 de votos afirmativos y 39,80 de negativos.

\subsection{Fase de consolidación del modelo diseñado (1986-1991)}

El referéndum de la OTAN marcó el final de la confusa ambigüedad que había presidido la política de seguridad y defensa del PSOE desde su llegada al poder. Solo a partir de ese momento, una vez culminado también el proceso de incorporación de España a las CE, pudo emprenderse una política exterior coherente y equilibrada.

\subsubsection{El modelo español de integración en la OTAN (1986-1991)}

El 13 de mayo de 1986, el embajador español se dirigió al secretario general de la OTAN para informarle de la forma en que el Gobierno de Madrid 
concebía su futuro papel en la Alianza. En aquella carta se esbozaban los aspectos más destacados del después llamado "modelo español" de integración, muy distinto del francés y del de los otros 14 países miembros (Sánchez 1990: 59):

- La defensa del territorio español era responsabilidad de todos los países de la OTAN y, a cambio, su situación geoestratégica y la disponibilidad de sus FAS vigorizaba sustancialmente la defensa común.

- La contribución militar española a la defensa común tendría lugar, preferentemente, dentro del espacio estratégico de interés nacional, en el que las FAS españolas se comprometían a desempeñar las siguientes misiones:

- Impedir la ocupación del territorio español.

- Desarrollar operaciones aéreas y navales en el Atlántico oriental.

- Mantener el control del estrecho de Gibraltar y sus accesos.

- Desarrollar operaciones aéreas y navales en el Mediterráneo occidental.

- Mantener el control del espacio aéreo y la defensa aérea en la zona de responsabilidad española y cooperación en las zonas adyacentes.

- Utilizar el espacio aéreo y el territorio español como áreas de tránsito, apoyo y logística de retaguardia.

- Cada uno de esos seis cometidos sería objeto de un Acuerdo de Coordinación entre las fuerzas españolas y aliadas, con las siguientes limitaciones:

- Las fuerzas españolas operarían fuera de la estructura militar integrada y siempre bajo mando nacional.

- En operaciones combinadas, se mantendrían bajo control operativo español o aliado, según procediese.

- No habría coordinación con los mandos aliados en Gibraltar.

- El Gobierno español retendría en todo momento y bajo cualquier circunstancia la decisión final para empeñar fuerzas españolas.

- Se establecerían procedimientos para coordinar el planeamiento español y aliado.

- Los estados de alerta de las fuerzas españolas serían análogos a los del sistema de alerta de la OTAN.

- Se redactarían directrices para desarrollar los Acuerdos de Coordinación.

- España participaría en el proceso de planeamiento de fuerzas, fuera de la estructura militar integrada, y cumplimentaría anualmente el 
Cuestionario de Planeamiento de Defensa.

- España participaría en ejercicios de los Cuarteles Generales de la OTAN y en los programas de ejercicios militares.

- Se establecerían enlaces con los mandos superiores aliados.

- Se coordinarían los sistemas de telecomunicaciones e información.

El diseño definitivo del modelo español se encomendó a un grupo de trabajo formado por militares y civiles, españoles y de los organismos de la Alianza, cuyo trabajo permitió que, el 18 de enero de 1988, llegara a establecerse el marco político-militar en el que se iba a desarrollar la contribución militar española y las directrices a que habrían de atenerse los Acuerdos de Coordinación que la regularían. Las conversaciones se prolongaron durante todo el año 1988, siendo muchos los obstáculos que hubo que sortear hasta que, el 10 de noviembre, el Comité Militar dio el visto bueno al proyecto elaborado. Salvadas sus objeciones, el documento fue aprobado sin dificultad por el Comité de Planeamiento de la Defensa el 23 de noviembre, por los jefes de Estado Mayor el día 29, por los ministros de Defensa el 1 de diciembre y por los jefes de Estado y de Gobierno del Consejo Atlántico al día siguiente (Pardo de Santayana 1989: 10-12).

En esencia, lo que se dilucidó a lo largo de 1988 fueron los cometidos concretos que la OTAN podía asignar a las FAS españolas y las limitaciones impuestas a dicha asignación. El siguiente paso fue normalizar los planes de defensa o de contingencia en los que participasen unidades españolas a través de sendos Acuerdos de Coordinación, uno por cada uno de los cometidos asumidos, tarea culminada en el verano de 1991 (Ferrús 1991: 46-47).

\subsubsection{Reducción de la presencia militar estadounidense (1986-1988)}

El siguiente paso, en consonancia con lo aprobado en el referéndum de 1986, era renegociar la relación bilateral con EEUU para reducir sus efectivos militares en España (Powell 2011; Viñas 2003). Las negociaciones fueron mucho más enconadas de lo esperado, debido a la firmeza de los representantes españoles al defender su postura y al escepticismo de los estadounidenses hacia la referida firmeza (Cajal 2010). El punto central a debatir era la salida de los 72 cazabombarderos F-16 del 401 Ala Táctica de la base de Torrejón, tema muy delicado para la opinión pública española. Una vez los estadounidenses estuvieron convencidos de la inmovilidad de la postura española, su reticencia al abandono se centró en tres puntos:

1. La firma del Tratado para la Reducción de Fuerzas Nucleares Intermedias había aumentado el valor de los F-16 de Torrejón en el 
esquema de seguridad de la OTAN, debido a su capacidad para portar armas nucleares.

2. La posible insolvencia del compromiso español para cumplir las misiones de los F-16 con aviones propios.

3. Los posibles efectos nocivos sobre las relaciones de EEUU con Grecia y Portugal, países que también pretendían reducir su presencia militar.

La postura española también generaba serias dudas en el seno de la OTAN sobre la fiabilidad y coherencia de un aliado que parecía anteponer sus intereses de política doméstica a los compromisos de seguridad adquiridos.

En este ambiente, que no era el mejor de los posibles, se firmó, el 15 de diciembre de 1988, el Convenio sobre Cooperación para la Defensa, que establecía un plazo de tres años desde su ratificación por el Parlamento español, para el abandono, prácticamente total, de la base de Torrejón, mantenía los conceptos de instalaciones de apoyo y autorizaciones de uso, definidos en 1982, y delimitaba los niveles autorizados de fuerzas estadounidenses en España. No obstante, su principal novedad era limitarlo al ámbito de la defensa y establecer una relación no basada en la búsqueda de contraprestaciones económicas, sino en intereses de seguridad mutua (Calvo 1993: 16-17).

Los recelos se fueron poco a poco superando y, con ocasión de la Primera Guerra del Golfo, quedó ampliamente demostrada la fiabilidad española. El Convenio demostró su utilidad durante la citada contienda, incluso superándose a menudo sus cláusulas, y España demostró que era un aliado fiable frente a muchas opiniones escépticas aparecidas en círculos especializados de EEUU. Se puso también en evidencia su valor geoestratégico como base de apoyo al despliegue de fuerzas en operaciones fuera del área OTAN y, más concretamente, en zonas del norte de África y del Cercano Oriente (Peck 1991: 23).

\subsubsection{El ingreso en la UEO (1985-1990)}

La sexta de las metas propuestas por Felipe González en el Decálogo de 1984 era la integración en la UEO, tal vez debido a que, unos meses antes, Helmut Schmidt, excanciller de la República Federal Alemana, había insistido en la necesidad de que los europeos potenciaran su propia defensa. Al año siguiente, en junio de 1985, el Partido Socialista francés lo volvió a reiterar $\mathrm{y}$, en la cumbre de Bonn de noviembre del mismo año, los jefes de Gobierno socialistas de los países miembros de la OTAN plantearon la necesidad de reformar la OTAN para otorgar mayores responsabilidades a Europa en materia de seguridad (Bardají 1987: 1268). 
El embrión de la UEO había sido el añejo Tratado de Alianza y Asistencia Mutua entre Francia y Reino Unido de 4 de marzo de 1947, más conocido como Tratado de Dunkerque. Al año siguiente, concretamente el 17 de marzo de 1948, es decir, un año antes del nacimiento de la OTAN y sobre el modelo del Tratado de Río de Janeiro suscrito entre EEUU y los países latinoamericanos el 2 de septiembre de 1947, Bélgica, Francia, Luxemburgo, Países Bajos y Reino Unido firmaron el Tratado de Bruselas. En él acordaron crear una Organización para la Defensa de la Unión Occidental. Pasados cinco años, el 27 de mayo de 1952, Alemania, Bélgica, Francia, Italia, Luxemburgo, Países Bajos y Reino Unido constituyeron la Comunidad Europea de Defensa, pero la no ratificación del parlamento francés abortó el proyecto.

El testigo fue recogido por Reino Unido y, el 25 de octubre de 1954, los Acuerdos de París modificaron el Tratado de Bruselas de 1948, pusieron fin a la ocupación militar de Alemania y dieron a luz la UEO. La UEO permaneció aletargada hasta octubre de 1984 -el mismo mes en que González anunciaba su propósito de incorporarse a ella-, momento en que la Declaración de Roma propuso revitalizarla. Tres años después, la Plataforma de La Haya la consideró esencial para la construcción de una Europa integrada, "que quedará incompleta hasta que no se considere el aspecto de su seguridad y defensa".

En el curso de la Cumbre Hispano-Alemana de septiembre de 1987, Felipe González se ofreció a integrar fuerzas españolas en la recién creada Brigada Franco-Alemana, lo que se interpretó como un gesto de aproximación a la UEO. Sin embargo, Reino Unido vetó que se cursase la preceptiva invitación mientras no se precisase el alcance de sus aportaciones militares a la OTAN (Rodríguez Santafé 1988: 11). Resuelto esto, el 18 de abril de 1988, mientras se negociaba en Bruselas el primer Acuerdo de Coordinación con la OTAN y se discutían en Madrid los términos del nuevo convenio defensivo con EEUU, el Consejo de Ministros de la UEO abrió sus puertas a España y Portugal. El 26 de mayo de 1988 se inició el proceso de negociación y el 14 de noviembre se firmó la adhesión, ratificada por el parlamento español en marzo de 1990 (Aguirre 1992: 22-23).

\section{Reforma de la justicia militar}

La reforma de la Justicia Militar, iniciada por Gutiérrez Mellado y culminada por Narcís Serra, fue fundamental para la inserción de las FAS en el Estado de Derecho y poner fin al tratamiento excepcional que disfrutaban desde tiempo inmemorial, reconocido de iure a finales del siglo $\mathrm{XIX}^{23}$. Y su

${ }^{23}$ Ley de Organización y Atribuciones de los Tribunales de Guerra, 14 de diciembre de 1883: Gaceta de Madrid de 16 de enero de 1884.

Araucaria. Revista Iberoamericana de Filosofia, Política, Humanidades y Relaciones Internacionales, año $23, \mathrm{n}^{\circ} 47$. Segundo cuatrimestre de 2021. Pp. 403-430. ISSN 1575-6823 e-ISSN 2340-2199 https://dx.doi.org/10.12795/araucaria.2021.i47.18 
fundamento legal fue la estricta aplicación del artículo 117.5 de la Constitución de 1978: "El principio de unidad jurisdiccional es la base de la organización y funcionamiento de los Tribunales. La ley regulará el ejercicio de la jurisdicción militar en el ámbito estrictamente castrense".

Una de las contrapartidas de los llamados Pactos de la Moncloa, suscritos por el Gobierno de Suárez con los partidos políticos, la patronal y los sindicatos el 27 de octubre de 1977, fue el compromiso de reducir las competencias de la jurisdicción militar. Pasarían tres años, no obstante, para que el Gobierno enviase a las Cortes un Proyecto de Ley para modificar parcialmente el Código de Justicia Militar (CJM) que había regido a todo lo largo del franquismo. Éste se había elaborado en 1890 y se había reformado en 1945, por lo que gran parte de su articulado vulneraba la Constitución y era objeto de continuos recursos ante el Tribunal Constitucional.

Al inicio de la Transición, la jurisdicción militar era totalmente independiente de la ordinaria, tenía su cúspide en el Consejo Supremo de Justicia Militar (CSJM) y se impartía por las llamadas "autoridades judiciales", encarnadas en los capitanes generales de Región Militar, en tiempo de paz, y en los generales jefes de los Ejércitos de Operaciones, en el de guerra. Ellas convocaban los consejos de guerra para dictar sentencia y de ellas dependían los Juzgados de Instrucción y la Fiscalía, todos ellos en manos de oficiales de las armas.

La necesidad de acomodar la jurisdicción militar a la Constitución y aproximarla en lo posible a la jurisdicción ordinaria, según lo acordado en los Pactos de la Moncloa, fue lo único que se reformó en 1980 (Millán 2003: 22). La Ley entonces aprobada se limitó a establecer el recurso de casación ante el Tribunal Supremo, crear Juzgados Togados de Instrucción, suprimir la figura del fiscal militar en tiempo de paz y atribuir estas dos últimas funciones a oficiales del Cuerpo Jurídico. Pero también se aprovechó el momento para anunciar la inmediata constitución de una Comisión que revisara totalmente la Justicia Militar, a la que se encomendó la siguiente tarea:

Elaborar un proyecto articulado del Código o Códigos referentes a la Justicia Militar antes de un año, a partir de su constitución, en el que se reflejen debidamente los principios jurídicos del orden constitucional nacional, la autonomía y especialidad de la Jurisdicción Militar, equilibradamente ponderada con la unidad procesal y sustantiva del ordenamiento jurídico y el sistema del poder judicial, así como el progreso comparado de los de la orgánica judicial militar de los Ejércitos de más asidua relación ${ }^{24}$.

${ }^{24}$ Ley Orgánica 9/1980, de 6 de noviembre, de reforma del Código de Justicia Militar, $1 .^{\mathrm{a}}$ y 2. disposiciones finales: BOE de 21 de noviembre de 1980. 
La citada Comisión, encabezada por el presidente del CSJM, llegó a elaborar un borrador de CJM y otro para armonizarlo con el régimen disciplinario de las FAS, más algunos estudios sobre diversos aspectos orgánicos y procesales de la jurisdicción militar. En 1982, al llegar el PSOE al Gobierno, se disolvió y sus trabajos se remitieron al Ministerio de Defensa. Sobre esta base, Narcís Serra, cuya principal preocupación era que la Justicia Militar no fuese un ente independiente del Poder Judicial y, por tanto, un centro de poder autónomo, encomendó a una nueva Comisión que procediese a elaborar una serie de Proyectos de Ley, inspirados esta vez en los siguientes principios rectores (Blay 1986: 476):

- Separar totalmente los ámbitos orgánico, procesal, penal y disciplinario, conforme al modelo establecido en la jurisdicción ordinaria y dejando de lado la tradición castrense de regular en un único código la organización de los tribunales, los procedimientos militares, la materia penal y las sanciones disciplinarias.

- Evitar la duplicidad de figuras delictivas en el Código Penal Común (CPC) y en el CJM, con especial énfasis en que la jurisdicción ordinaria conociese en exclusiva del delito de rebelión.

- Eliminar la pena de muerte en tiempo de paz.

- Suavizar las penas y potenciar la discrecionalidad del juzgador.

- Preceptuar y automatizar la responsabilidad civil subsidiaria de las FAS.

- Diferenciar la responsabilidad penal de los militares profesionales respecto a la de la tropa y marinería de reemplazo.

A consecuencia de ello, un nuevo Código Penal Militar (CPM) fue enviado a las Cortes en noviembre de 1984, junto con el preparado por el Ministerio de Justicia para adaptar a éste el vigente CPC. En su redacción se advertía la influencia de diversos códigos militares extranjeros, con notorias aportaciones del alemán de 1974, del portugués de 1977, del belga de 1978 y del francés de 1982, y ninguna del británico ni del estadounidense, cosa lógica teniendo en cuenta que la legislación penal de ambos países no se atenía al Derecho Romano, del que se derivaba la española (Rodríguez-Villasante 1986: 373375).

El trámite parlamentario fue especialmente largo y complejo, al advertir la ponencia que dictaminó el proyecto gubernamental que podría producirse un vacío legal si no se simultaneaba su aprobación con la del régimen disciplinario. Además, tanto en el Congreso de los Diputados como en el Senado se introdujeron bastantes enmiendas al articulado. Todo ello ocasionó que la Ley tardase un año en aprobarse, postergándose además su entrada en 
vigor hasta el 1 de junio de 1986, única forma de hacerla coincidir con la del referido régimen disciplinario ${ }^{25}$.

Sin duda, el aspecto más llamativo del nuevo CPM era su condición de norma complementaria del CPC. También era totalmente novedosa la pérdida de competencias de la jurisdicción militar sobre el personal civil que cometiese delitos contra la institución militar, competencia que se remontaba a la llamada Ley de Jurisdicciones de 1906, así como la eliminación de los delitos contra el honor militar. Y entre sus aspectos más positivos cabría señalar las cuidadas definiciones de las figuras penales, la sistematización de los delitos, la simplificación de las penas y la introducción de un título dedicado a los delitos contra las leyes y usos de la guerra (Pignatelli 1996).

Dos meses después, el Gobierno remitió a las Cortes la norma que debía regular el régimen disciplinario de las FAS, cuyo objetivo era velar por el mantenimiento de la disciplina y facultar al mando militar para corregir las faltas de sus subordinados. Sus peripecias parlamentarias fueron menos complejas e incluso se aprobó antes que el CPM, haciéndose coincidir, no obstante, sus fechas de entrada en vigor ${ }^{26}$. Su aspecto más revolucionario fue el establecimiento de garantías en el proceso sancionador, reconociéndose el derecho del infractor a recurrir por vía administrativa o jurisdiccional la sanción impuesta. También era novedosa la minuciosa tipificación de las infracciones, conforme al mandato del artículo 25.1 de la Constitución, o la disminución de la duración máxima de las sanciones con privación de libertad, es decir, los tradicionales arrestos (Rodríguez-Villasante 1996: 38). Respecto a la reforma de la justicia castrense, ésta fue la norma jurídica que mayor impacto tuvo en el ámbito militar, al ser la de más directa aplicación al ejercicio ordinario del mando. Así lo destacaría un comandante ocho años después de su entrada en vigor:

Poco más de ocho años de vigencia de la Ley Orgánica 12/1985, de 27 de noviembre, del Régimen Disciplinario de las Fuerzas Armadas, no parecen haber sido suficientes para que esta norma legal haya calado con la intensidad debida en el estamento castrense, y no precisamente porque haya reticencia a la hora de aplicarla, sino porque, frente a la inmediatez a la que nos tenía acostumbrados el Código de Justicia Militar a la hora de sancionar disciplinariamente las faltas cometidas por los militares, la nueva ley impone, en aras de la seguridad jurídica, la exigencia de seguir un procedimiento, que, si bien puede y debe ser breve y expedito, es innegable que "asusta" a quienes por primera vez, o de forma esporádica, tienen que vérselas con él (Martín 1995: 840).

${ }^{25}$ Ley Orgánica 13/1985, de 9 de diciembre, de Código Penal Militar: BOE de 11 de diciembre de 1985.

${ }^{26}$ Ley Orgánica 12/1985, de 27 de noviembre, del Régimen Disciplinario de las Fuerzas Armadas: BOE de 29 de noviembre de 1985. 
El siguiente paso fue reformar la anticonstitucional organización de la Justicia Militar. La Ley aprobada a ese efecto, aparte de abolir inmemoriales principios y privilegios, proclamaba que las bases sobre las que se sustentaba la jurisdicción ordinaria y la jurisdicción militar eran exactamente las mismas ${ }^{27}$. A tal objeto, se contemplaba la implantación de las siguientes instancias judiciales (Millán 2003: 44-45):

- Sala de lo Militar del Tribunal Supremo, integrada por ocho magistrados -cuatro procedentes de la Carrera Judicial y otros tantos del Cuerpo Jurídico Militar- con el cometido de juzgar en única instancia a los generales y almirantes de tres y cuatro estrellas, resolver los recursos de casación y supervisar el ejercicio de las facultades disciplinarias.

- Tribunal Militar Central, con sede en Madrid y competencia nacional para juzgar a los oficiales de empleo igual o superior a comandante y resolver recursos contencioso-disciplinarios, e integrado permanentemente por cinco oficiales generales del Cuerpo Jurídico Militar. Para las vistas de los procesos penales y contenciosodisciplinarios, se preveía formar una sala presidida por un consejero togado y constituida por dos vocales - un general auditor y un general de brigada o contralmirante del ejército de procedencia del imputado-, reminiscencia de la tradicional composición mixta de los antiguos consejos de guerra, amparada en lo previsto para el Jurado en la Constitución.

- Tribunales Militares Territoriales, integrados permanentemente, a semejanza del anterior, por cinco oficiales del Cuerpo Jurídico y puntualmente por dos jurídicos y un comandante o capitán de corbeta.

- Juzgados Togados Militares de Instrucción, encomendados en exclusiva al Cuerpo Jurídico.

- Fiscalía Militar, dependiente de la Fiscalía General del Estado y desempeñada por un general auditor, que actuaba como fiscal jefe de la Sala de lo Militar, quedando subordinados a él los fiscales de los demás tribunales castrenses.

- Defensa letrada en todos los casos, salvo en el extranjero y en alta mar.

El último eslabón de aquel trascendental proceso reformista tuvo como objeto acomodar los procedimientos judiciales militares a la Ley de Enjuiciamiento Criminal, aunque adaptada a sus peculiaridades específicas ${ }^{28}$. Con ello se pretendía aumentar las garantías judiciales, asegurar la igualdad de

${ }^{27}$ Ley Orgánica 4/1987, de 15 de julio, de la Competencia y Organización de la Jurisdicción Militar: BOE de 18 de julio de 1987.

${ }^{28}$ Ley Orgánica 2/1989, de 13 de abril, Procesal Militar: BOE de 18 de abril de 1989.

Araucaria. Revista Iberoamericana de Filosofia, Política, Humanidades y Relaciones Internacionales, año $23, \mathrm{n}^{\circ} 47$. Segundo cuatrimestre de 2021. Pp. 403-430. ISSN 1575-6823 e-ISSN 2340-2199 https://dx.doi.org/10.12795/araucaria.2021.i47.18 
las partes en el proceso penal, dar opción a personarse la acusación particular, garantizar la asistencia letrada desde el inicio del procedimiento, unificar la dispersa normativa que regulaba el procedimiento para detener a los militares, proceder sumariamente para juzgar con urgencia los delitos de deserción y fraude, y sumarísimamente para ciertos delitos cometidos en tiempo de guerra.

\section{Conclusión}

Entre los principales beneficios obtenidos de este largo y complejo proceso de modernización de la estructura de defensa y seguridad española, cabría destacar: la identificación de los miembros de las FAS con el ordenamiento constitucional, la normalización de su relación con el resto de administraciones públicas, su compromiso con las misiones y funciones asignadas por los poderes democráticos, su entrega y sacrificio en las operaciones internacionales para el mantenimiento de la paz y su vocación de servicio y elevado profesionalismo para garantizar la seguridad y actuar en caso de catástrofes naturales. Todos esos elementos han contribuido muy positivamente a que, en la actualidad, las FAS ocupen un lugar muy destacado entre las instituciones más valoradas por la opinión pública.

\section{Bibliografía:}

M. Aguilar Olivencia, El ejército español durante la transición a la democracia, Madrid, Letrame, 2019.

J. Aguirre Scandella, "Hacia una nueva arquitectura de seguridad específicamente europea", en Ejército, 633 (1992), pp. 22-27.

C. del Arenal, "La posición exterior de España" [en Ramón Cotarelo (comp.), Transición política y consolidación democrática. España 1975-1986, Madrid, CIS, 1992], pp. 389-428.

R. L. Bardají, "La defensa europea: ¿mito o realidad?”, en Revista de Aeronáutica y Astronáutica, 564 (1987), pp. 1268-1269.

F. Blay Villasante, "Líneas fundamentales de la reforma de la Justicia Militar", en Revista de Aeronáutica y Astronáutica, 545 (1986), pp. 476-481.

M. Cajal, Sueños y pesadillas: memorias de un diplomático, Barcelona, Tusquets, 2010.

C. Calvo González-Regueral, "Relaciones hispano-norteamericanas en materia de Defensa", en Ejército, 645 (1993), pp. 14-19.

L. Ferrús Gabaldón, "Los acuerdos de coordinación con la OTAN", en Revista de Aeronáutica y Astronáutica, 600 (1991), pp. 46-48.

M. Fraga Iribarne, "La Constitución de 1978 a vista de ponente", en Documentación Administrativa, 180 (1978), pp. 9-18.

M. Gutiérrez Mellado, Un soldado de España. Conversaciones con Jesús Picatoste, Barcelona, Argos Vergara, 1983. 
Ley Orgánica por la que se regulan los Criterios Básicos de la Defensa Nacional y la Organización Militar. Trabajos parlamentarios, Madrid, Cortes Generales, s. a.

A. Marquina, España en la política de seguridad occidental, 1939-1986, Madrid, EME, 1986.

J. C. Martín Torrijos, "Sobre el régimen disciplinario de las Fuerzas Armadas", en Revista de Aeronáutica y Astronáutica, 647 (1995), pp. 840-845.

J. Martínez-Esparza Valiente, "España en la Alianza Atlántica, siete años después", en Revista de Aeronáutica y Astronáutica, 580 (1989), pp. 429-434.

F. Medina, Memoria oculta del Ejército: los militares se confiesan (1970-2004), Madrid, Espasa, 2004.

A. Millán Garrido, "La reforma de la Justicia militar en España" [en Antonio Millán Garrido (ed.), Justicia Militar, Barcelona, Ariel, 2003], pp. 13-94.

J. del Olmo, "El Ministerio de Defensa (1977-1984)" [en Isidro Sepúlveda y Sonia Alda (eds.), Fuerzas Armadas y políticas de Defensa: transición y modernización, Madrid, IUGM-UNED, 2007], pp. 309-330.

J. Ortega Martín, La transformación de los ejércitos españoles (1975-2008). Madrid: UNED-IUGM, 2008.

J. R. Pardo de Santayana, “Contribución española a la OTAN", en Ejército, 589 (1989), pp. 10-12.

M. Peck, "Closer US-Spanish ties evolve", en Defense News (junio 1991), pp. 23-24.

F. Pignatelli y Meca, "El Código Penal Militar: perspectivas de Lege Ferenda", en Estudios de Derecho Judicial, 5 (1996), pp. 89-170.

Por el cambio. Programa electoral. Partido Socialista Obrero Español, Madrid, s. n., 1982.

F. Portero, "La política de seguridad, 1975-1988" [en Javier Tusell, Juan Avilés y Rosa Pardo (eds.), La política exterior de España en el siglo XX, Madrid, UNED-Biblioteca Nueva, 2000], pp. 473-510.

C. Powell, "Cambio de régimen y política exterior: España, 1975-1989" [en Javier Tusell, Juan Avilés y Rosa Pardo (eds.), La política exterior de España en el siglo XX, Madrid, UNED-Biblioteca Nueva, 2000], pp. 413-454.

C. Powell, El amigo americano. España y Estados Unidos: de la dictadura a la democracia, Barcelona, Galaxia Gutenberg, 2011.

F. Puell de la Villa, Historia del ejército en España, 2. ${ }^{a}$ ed., Madrid, Alianza, 2005.

F. Puell de la Villa, "La creación del Ministerio de Defensa (1968-1977)" [en Isidro Sepúlveda y Sonia Alda (eds.), Fuerzas Armadas y políticas de defensa: transición y modernización, Madrid, IUGM-UNED, 2007], pp. 297-304.

F. Puell de la Villa, "La política de seguridad y defensa" [en Álvaro Soto Carmona y Abdón Mateos López (dirs.): Historia de la época socialista. España: 1982-1996, Madrid, Sílex, 2013], pp. 43-63.

F. Puell de la Villa, "Un rey con sólida formación militar” [en José Luis García Delgado (ed.), Rey de la democracia, Barcelona, Galaxia Gutenberg, 2017], pp. 115-145.

F. Puell de la Villa, Gutiérrez Mellado y su tiempo 1912-1995, Madrid, Alianza, 2019.

Resoluciones del 29 Congreso del PSOE, 21-24 Octubre 1981. Anexo del Acta de Resoluciones. Madrid: s. n., 1981.

F. Rodrigo, "La inserción de España en la política de seguridad occidental” [en Richard Gillespie, Fernando Rodrigo y Jonathan Story (eds.), Las relaciones exteriores de la España democrática, Madrid, Alianza, 1995], pp. 77-103. 
S. Rodríguez Santafé, “España y la Unión Europea Occidental”, en Ejército, 583 (1988), pp. 10-16.

J. L. Rodríguez-Villasante y Prieto, "La reforma de la Justicia Militar", en Revista General de Marina, 210 (marzo 1986), pp. 369-388.

J. L. Rodríguez-Villasante y Prieto, "Régimen disciplinario militar", en Ejército, 672 (1996), pp. 36-41.

J. Sánchez Méndez, "Valoración geoestratégica y militar de la adhesión de España a la OTAN", en Revista de Aeronáutica y Astronáutica, 580 (1989), pp. 435-446.

J. Sánchez Méndez, "La década de los 80: nuestra adhesión a la Alianza Atlántica. Los acuerdos de coordinación: modelo español de participación en la OTAN", en Revista de Aeronáutica y Astronáutica, 590 (1990), pp. 57-63.

N. Serra, La transición militar. Reflexiones en torno a la reforma democrática de las fuerzas armadas, Barcelona, Debate, 2008.

A. Viñas, En las garras del águila: los pactos con Estados Unidos, de Francisco Franco a Felipe González (1945-1995), Barcelona, Crítica, 2003. 